Guido J. Reiss* and Maik Wyshusek

\title{
The layered crystal structure of bis(theophyllinium) hexachloridostannate (IV), $\mathrm{C}_{14} \mathrm{H}_{18} \mathrm{~N}_{8} \mathrm{O}_{8} \mathrm{SnCl}_{6}$
}

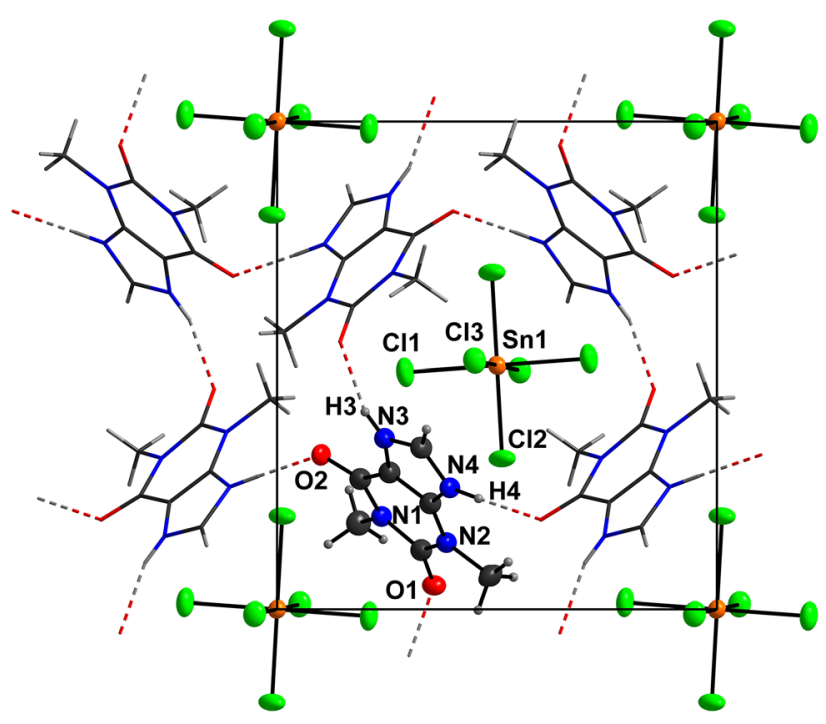

https://doi.org/10.1515/ncrs-2021-0185

Received May 13, 2021; accepted June 14, 2021;

published online July 6, 2021

\begin{abstract}
$\mathrm{C}_{14} \mathrm{H}_{18} \mathrm{~N}_{8} \mathrm{O}_{8} \mathrm{SnCl}_{6}$, monoclinic, $P 2_{1} / n$ (no. 14), $a=8.1810(2) \AA, b=12.6195(3) \AA, c=11.3811(2) \AA$, $\beta=90.258(2)^{\circ}, Z=2, V=1174.97(5) \AA^{3}, R_{\mathrm{gt}}(F)=0.0266$, $w R_{\text {ref }}=0.0620, T=290 \mathrm{~K}$.
\end{abstract}

CCDC no.: 2089778

Table 1 contains crystallographic data and Table 2 contains the list of the atoms including atomic coordinates and displacement parameters.

*Corresponding author: Guido J. Reiss, Institut für Anorganische Chemie und Strukturchemie, Lehrstuhl II: Material- und Strukturforschung, Heinrich-Heine-Universität Düsseldorf, Universitätsstrasse 1, D-40225 Düsseldorf, Germany, E-mail: reissg@hhu.de. https://orcid.org/0000-0002-3004-3955 Maik Wyshusek, Institut für Anorganische Chemie und Strukturchemie Lehrstuhl II: Material- und Strukturforschung, Heinrich-Heine-Universität Düsseldorf, Universitätsstrasse 1, D-40225 Düsseldorf, Germany, E-mail: Maik.Wyshusek@hhu.de
Table 1: Data collection and handling.

\begin{tabular}{|c|c|}
\hline Crystal: & Colourless block \\
\hline Size: & $0.30 \times 0.16 \times 0.10 \mathrm{~mm}$ \\
\hline Wavelength: & Mo $K \alpha$ radiation $(0.71073 \AA$ ) \\
\hline$\mu:$ & $1.81 \mathrm{~mm}^{-1}$ \\
\hline Diffractometer, scan mode: & Xcalibur EOS, $\omega$ \\
\hline$\theta_{\max }$, completeness: & $33.0^{\circ}, 98 \%$ \\
\hline$N(h k l)_{\text {measured }}, N(h k l)_{\text {unique }}, R_{\text {int }}:$ & $17679,4333,0.025$ \\
\hline Criterion for $I_{\mathrm{obs}}, N\left(h k l_{\mathrm{gt}}\right.$ : & $I_{\mathrm{obs}}>2 \sigma\left(I_{\mathrm{obs}}\right), 3278$ \\
\hline$N(\text { param })_{\text {refined }}$ & 165 \\
\hline Programs: & $\begin{array}{l}\text { Diamond [1], CrysAlis }{ }^{\mathrm{PRO}}[2] \text {, } \\
\text { SHELX }[3,4] \text {, ShelXle [5] }\end{array}$ \\
\hline
\end{tabular}

\section{Source of material}

All chemicals were obtained from commercial sources and used as purchased. The Raman spectra were measured using a Bruker MULTIRAM spectrometer (Nd: YAG-laser at $1064 \mathrm{~nm}$; InGaAs detector) with an apodized resolution of $8 \mathrm{~cm}^{-1}$ in the region of $4000-70 \mathrm{~cm}^{-1}$. The title compound was synthesized by dissolving $0.18 \mathrm{~g}(1 \mathrm{mmol})$ theophylline 180.16 and $0.14 \mathrm{SnCl}_{4}(0.5 \mathrm{mmol})$ in $1 \mathrm{~mL}$ concentrated hydrochloric acid. Short-time warming until both components were dissolved yielded a colourless solution. From the aforementioned colourless solution a large number of colourless block crystals grew upon slow cooling to room temperature within minutes.

\section{Experimental details}

A single crystal of the title compound was directly selected from the mother liquor and rapidly transferred to the Xcalibur four-circle diffractometer equipped with an EOS detector [2]. An absorption correction (Gaussian method) was applied [2]. The structure solution and the refinement were successfully carried out using the SHELX program system [3-5]. The pseudo-orthogonal unit cell (see the Figure and the Abstract) and the occupancy of special positions by the $\mathrm{SnCl}_{6}{ }^{2-}$ anions causes a couple of minor difficulties during the semi-automated data collection 
Table 2: Fractional atomic coordinates and isotropic or equivalent isotropic displacement parameters $\left(\AA^{2}\right)$.

\begin{tabular}{lrrrr}
\hline Atom & $\boldsymbol{x}$ & $\boldsymbol{y}$ & $\boldsymbol{z}$ & $\boldsymbol{U}_{\text {iso }} \boldsymbol{U}_{\text {eq }}$ \\
\hline Sn1 & 0.500000 & 0.500000 & 0.500000 & $0.02128(5)$ \\
Cl1 & $0.43257(7)$ & $0.48605(6)$ & $0.70878(5)$ & $0.04115(14)$ \\
Cl2 & $0.51798(9)$ & $0.30903(4)$ & $0.48832(6)$ & $0.04624(17)$ \\
Cl3 & $0.21278(6)$ & $0.49002(5)$ & $0.44895(5)$ & $0.03561(12)$ \\
O1 & $0.52203(19)$ & $0.04847(13)$ & $0.64313(15)$ & $0.0351(4)$ \\
O2 & $0.63937(19)$ & $0.31667(13)$ & $0.90004(14)$ & $0.0324(3)$ \\
N1 & $0.5731(2)$ & $0.19005(14)$ & $0.76250(16)$ & $0.0268(3)$ \\
N2 & $0.7595(2)$ & $0.13645(13)$ & $0.61508(15)$ & $0.0259(3)$ \\
N3 & $0.9486(2)$ & $0.35070(15)$ & $0.75585(16)$ & $0.0276(4)$ \\
H3 & $0.953(3)$ & $0.405(2)$ & $0.800(2)$ & $0.037(7)^{\star}$ \\
N4 & $1.0039(2)$ & $0.24896(15)$ & $0.60733(17)$ & $0.0296(4)$ \\
H4 & $1.052(4)$ & $0.227(2)$ & $0.542(3)$ & $0.054(9)^{\star}$ \\
C1 & $0.6133(3)$ & $0.12098(16)$ & $0.67220(19)$ & $0.0265(4)$ \\
C2 & $0.8569(2)$ & $0.21706(16)$ & $0.65178(18)$ & $0.0251(4)$ \\
C3 & $0.8203(2)$ & $0.28065(16)$ & $0.74453(17)$ & $0.0243(4)$ \\
C4 & $0.6753(2)$ & $0.26708(16)$ & $0.81081(18)$ & $0.0251(4)$ \\
C5 & $1.0552(3)$ & $0.33142(18)$ & $0.6724(2)$ & $0.0316(4)$ \\
H5 & 1.151389 & 0.369097 & 0.660252 & $0.043(7)^{*}$ \\
C6 & $0.4111(3)$ & $0.1765(2)$ & $0.8148(2)$ & $0.0389(5)$ \\
H6A & 0.367669 & 0.244483 & 0.835927 & $0.064(6)^{*}$ \\
H6B & 0.419974 & 0.132962 & 0.883729 & $0.064(6)^{*}$ \\
H6C & 0.339429 & 0.143028 & 0.758983 & $0.064(6)^{*}$ \\
C7 & $0.7991(3)$ & $0.0684(2)$ & $0.5151(2)$ & $0.0408(6)$ \\
H7A & 0.707185 & 0.065270 & 0.462509 & $0.100(8)^{*}$ \\
H7B & 0.824267 & -0.001657 & 0.542783 & $0.100(8)^{\star}$ \\
H7C & 0.891865 & 0.096789 & 0.474470 & $0.100(8)^{\star}$ \\
\hline & & & &
\end{tabular}

strategy calculation. But an extended exposure time provides a reasonable $I / \sigma$ ratio for the systematically weak reflections $\left(R(\sigma)=0.0259 ; R(\sigma)=\Sigma\left[\sigma\left(F_{o}^{2}\right)\right] / \Sigma\left[F_{o}^{2}\right]\right)$ and guarantees a plausible chemical model $[6,7]$. In this case the resolution limit was set to $0.65 \AA$ yielding a reflections/ parameter ratio of 26.3/1. All hydrogen atoms were seen in the Fourier map after all non-hydrogen atoms were located. C-bound hydrogen atoms were included using a riding model. Coordinates of nitrogen-bound hydrogen atoms were refined using distance restraints and individually refined $\mathrm{U}_{\text {iso }}$ parameters. The maximum residual peak of $0.81 \mathrm{e}^{-3}$ and the deepest hole of $-0.71 \mathrm{e}^{-3}$ are found 0.66 and $0.70 \AA$, respectively, from atom $\mathrm{Cl} 2$.

\section{Comment}

\section{Introduction}

Theophylline is a well-known natural product and was first described by Kossel in 1888 [8, 9]. He was able to isolate theophylline from tea leaves, which origins the naming up to now. There is still a fundamental interest in this compound and the corresponding solid state phases [10, 11] and co-crystals [12-15]. Nowadays theophylline is often used as pharmaceutical agent due to its effects on the respiratory system [16-19]. Recently, theophylline was also used in SARS-CoV-2 therapy [20].

We have already shown that heterocyclic cations like some pyridinium derivatives $[21,22]$ and the derived $\mathrm{N}$ protonated cations of naturally occurring bases like nicotine [23, 24], caffeine [25] and theophylline [26, 27] are excellent tectons to construct hydrogen bonded networks. A database check (Cambridge Structural database [28]) showed that not more than about 20 crystal structures have been deposited so far, that contain a theophyllinium cation. The $\mathrm{SnCl}_{6}{ }^{2-}$ counterion used for this study is a bulky, medium-strong hydrogen-bond acceptor, which is sometimes used by us [29] and many other groups [30-36]. It should be mentioned that anionic Sn(IV) complexes are of current interest with mixed ligands that contain chlorido ligands and for example $\mathrm{C}_{2} \mathrm{~F}_{5}$ [37] groups or benzyl groups [38], respectively. This contribution is part of our longstanding interest in the structures and hydrogen-bonding schemes of hexahalogenidometallates [6, 39].

From the reaction of theophylline (systematic name: 1,3-dimethyl-3,7-dihydro-1 $\mathrm{H}$-purine-2,6-dione) with hydrochloric in the presence of one equivalent of $\mathrm{SnCl}_{4}$, colorless block crystals of the title compound were obtained.

\section{Structural comments}

The asymmetric unit of the title compound consists of one $\mathrm{N}$ protonated theophyllinium cation (TheoH) residing on a general position, and one half of a hexachloridostannate(IV) anion located on an inversion center. Bond lengths within the TheoH cation are all in the expected ranges [26, 27]. The same is true for the $\left[\mathrm{SnCl}_{6}\right]^{2-}$ anion [29-36]. In detail, the $\mathrm{Sn}-$ $\mathrm{Cl}$ distances range from 2.4182(5)-2.4482(6) $\AA$ and the cisangles range from 89.63(2)-90.37(2) ${ }^{\circ}$. Each theophyllinium cation is connected to four neighbouring cations by classical $\mathrm{NH} \cdots \mathrm{O}$ hydrogen bonds (see the Figure). These connections construct a layered, hydrogen bonded structure in the (101) plane. In detail, the $\mathrm{N}-\mathrm{H}$ donor groups of TheoH are involved in unbifurcated classical hydrogen bond (see the Figure; $\mathrm{N} 3 \cdots 01^{\prime}=2.758(2) \AA{ }^{\prime}{ }^{\prime}=1.5-x, 0.5+y, 1.5-z ; \mathrm{N} 4 \cdots$ $\left.02^{\prime \prime}=2.739(2) \AA \AA^{\prime \prime}=0.5+x, 0.5-y,-0.5-z\right)$. Each mesh of the hydrogen-bonded net consists of four cations. It is obvious that larger and smaller meshes are present in this structure (see the Figure). Consequently, the $\left[\mathrm{SnCl}_{6}\right]^{2-}$ anions (Wyckoff site: $2 a$ ) are located beneath and above of the larger meshs, whereas two inversion symmetry related 
methyl groups of two TheoH cations fill the smaller meshes around the Wyckoff sites $2 b$ and $2 c$.

The $\left[\mathrm{SnCl}_{6}\right]^{2-}$ anion as a weak to medium-strong hydrogen-bond acceptor is not involved in any strong hydrogen bonds in the title structure. This was bound to happen as all classsic hydrogen donors in the title structure are involved in medium-strong unbifurcated $\mathrm{NH} \cdots \mathrm{O}$ hydrogen bonds. Nevertheless the chlorido ligand $\mathrm{Cl} 2$, which features the shortest $\mathrm{Sn}-\mathrm{Cl}$ distance shows the longest $\mathrm{Cl} \cdots \mathrm{H}$ distance, which is in total accord with our expectations of a bulky anion interacting with neighbours via weak intermolecular forces. Thus we suppose that the shape and the group radius of the $\left[\mathrm{SnCl}_{6}\right]^{2-}$ determines or at least supports the formation of the hydrogen-bonded, twodimensional network.

This suggestion is supported by the fact the in the case of another theophyllinium salt $\left(\mathrm{I}_{10}{ }^{2-} ;\right.$ [26]) a related hydrogen bonded 2D network is obtained, which features only one type of a mesh formed by six theophyllinium cations. Also in the case of the (TheoH) $)_{2} \mathrm{I}_{10}$, the cyclic $\mathrm{I}_{10}{ }^{2-}$ anions excellently fits with the shape of the hydrogenbonded network formed by the TheoH cations.

\section{Raman spectroscopy}

There are three very strong signals in the Raman spectrum at 312,162 , and $135 \mathrm{~cm}^{-1}$ respectively as well as one medium-strong signal at $239 \mathrm{~cm}^{-1}$. These four signals must be assigned to the $\mathrm{SnCl}_{6}{ }^{2-}$ anion and are similar to those for detected for $\left(\mathrm{PCl}_{4}\right)_{2} \mathrm{SnCl}_{6}[40]$ and $\mathrm{K}_{2} \mathrm{SnCl}_{6}[41]$.

\section{Conclusion and outlook}

We have shown that the counter anion may influence the hydrogen-bonding scheme of the theophyllinium sub system. Also typical for this class of compounds is the pseudosymmetric arrangement [42-45] of the anionic sub structure of the hexachloridostannate(IV) anions [39, 46]. We expect that further theophyllinium hexahalogenidometallate salts will be accessible using other metalchlorides as educts: $M=\operatorname{Ir}$ [39], $\mathrm{Pb}$ [46], Os [30], Pt [30].

Author contributions: All the authors have accepted responsibility for the entire content of this submitted manuscript and approved submission.

Research funding: We gratefully acknowledge support by the Ministry of Innovation, Science and Research of NorthRhine Westphalia and the German Research Foundation
(DFG) for financial support (Xcalibur diffractometer; INST 208/533-1, project no. 162659349). Finally, funding by the open access fund of the Heinrich-Heine-Universität Düsseldorf is also gratefully acknowledged.

Conflict of interest statement: The authors declare no conflicts of interest regarding this article.

\section{References}

1. Brandenburg K. DIAMOND. Visual Crystal Structure Information System. Ver.4.5.2; Crystal Impact: Bonn, Germany, 2018.

2. Oxford Diffraction. CrysAlis ${ }^{P R O}$. (version 1.171.33.42); Oxford Diffraction Ltd.: Oxford, UK, 2009.

3. Sheldrick G. M. A short history of SHELX. Acta Crystallogr. 2008, A64, 112-122.

4. Sheldrick G. M. Crystal structure refinement with SHELXL. Acta Crystallogr. 2015, C71, 3-8.

5. Hübschle C. B., Sheldrick G. M., Dittrich B. ShelXle: a Qt graphical user interface for SHELXL. J. Appl. Crystallogr. 2011, 44, 1281-1284.

6. Reiss G. J. A reinvestigation of Wilm's salt, $\left(\mathrm{NH}_{4}\right)_{4}\left[\mathrm{RhCl}_{6}\right] \mathrm{NO}_{3}-$ structure, spectroscopy and thermal analysis -. Z. Kristallogr. . Cryst. Mater. 2002, 217, 550-556.

7. Megen M., Reiss G. J. The pseudosymmetric structure of bis(pentane-1,5-diaminium) iodide tris(triiodide). Acta Crystallogr. E 2012, 68, 01331-01332.

8. Kossel A. Ueber eine neue Base aus dem Pflanzenreich. Ber. Dtsch. Chem. Ges. 1888, 21, 2164.

9. Kossel A. Ueber das Theophyllin, einen neuen Bestandtheil des Thees. Z. Physiolog. Chem. 1889, 13, 298-308.

10. Fucke K., McIntyre G. J., Wilkinson C., Henry M., Howard J. A., Steed J. W. New insights into an old molecule: interaction energies of theophylline crystal forms. Cryst. Growth Des. 2012, $12,1395-1401$.

11. Matsuo K., Matsuoka M. Solid-state polymorphic transition of theophylline anhydrate and humidity effect. Cryst. Growth Des. 2007, 7, 411-415.

12. Darwish S., Zeglinski J., Krishna G. R., Shaikh R., Khraisheh M., Walker G. M., Croker D. M. A new 1:1 drug-drug cocrystal of Theophylline and Aspirin: discovery, characterization, and construction of ternary phase diagrams. Cryst. Growth Des. 2018, 18, 7526-7532.

13. Wang L., Luo M., Li J., Wang J., Zhang H., Deng Z. Sweet Theophylline cocrystal with two tautomers of acesulfame. Cryst. Growth Des. 2015, 15, 2574-2578.

14. McTague H., Rasmuson A. C. Nucleation of the theophylline: salicylic acid 1:1 cocrystal. Cryst. Growth Des. 2021, 21, 2711-2719.

15. Lange L., Sadowski G. Polymorphs, hydrates, cocrystals, and cocrystal hydrates: thermodynamic modeling of theophylline systems. Cryst. Growth Des. 2016, 16, 4439-4449.

16. Persson C. G. A. Overview of effects of theophylline. J. Allergy Clin. Immunol. 1986, 78, 780-787.

17. Sofian Z. M., Benaouda F., Wang J. T. W., Lu Y., Barlow D. J., Royall P. G., Farag D. B., Rahman K. M., Al Jamal K. T., Forbes B., Jones S. A. A Cyclodextrin stabilized spermine tagged drug triplex 
that targets Theophylline to the lungs selectively in respiratory emergency. Adv. Ther. 2020, 3, 2000153.

18. Benaouda F., Jones S. A., Chana J., Dal Corno B. M., Barlow D. J., Hider R. C., Page C. P., Forbes B. Ion-pairing with spermine targets Theophylline to the lungs via the polyamine transport system. Mol. Pharm. 2018, 15, 861-870.

19. Tanaka R., Hattori Y., Otsuka M., Ashizawa K. Application of spray freeze drying to theophylline-oxalic acid cocrystal engineering for inhaled dry powder technology. Drug Dev. Ind. Pharm. 2020, 46, 179-187.

20. Zhou C., Gao C., Xie Y., Xu M. COVID-19 with spontaneous pneumomediastinum. Lancet Infect. Dis. 2020, 20, 510.

21. Reiss G. J., Leske P. B. The twinned crystal structure of bis(4aminopyridin-1-ium) iodide triiodide, $\mathrm{C}_{20} \mathrm{H}_{28} \mathrm{I}_{8} \mathrm{~N}_{8}$. Z. Kristallogr. N. Cryst. Struct. 2014, 229, 452-454.

22. Reiss G. J., van Megen M. Two new polyiodides in the 4,4'-bipyridinium diiodide/iodine system. Z. Naturforsch. B Chem. Sci. 2012, 67, 5-10.

23. Reiss G. J. I ${ }_{5}$ polymers with a layered arrangement: synthesis, spectroscopy, and structure of a new polyiodide salt in the nicotine $/ \mathrm{HI} / \mathrm{I}_{2}$ system. Z. Naturforsch. B Chem. Sci. 2015, 70, 735-740.

24. Reiss G. J., Sergeeva A. Hydrogen bonding versus packing effects in the crystal structure of 3-((1R, 2S)-1-methylpyrrolidin-1-ium-2yl) pyridin-1-ium tetraiodidozincate(II). Z. Kristallogr. N. Cryst. Struct. 2020, 235, 959-962.

25. Merkelbach J., Majewski M. A., Reiss G. J. Crystal structure of caffeinium triiodide-caffeine (1/1), $\mathrm{C}_{16} \mathrm{H}_{21} \mathrm{I}_{3} \mathrm{~N}_{8} \mathrm{O}_{4}$. Z. Kristallogr. $N$. Cryst. Struct. 2018, 233, 941-944.

26. Reiss G. J. A cyclic $\mathrm{I}_{10}{ }^{2-}$ anion in the layered crystal structure of theophyllinium pentaiodide, $\mathrm{C}_{7} \mathrm{H}_{9} \mathrm{I}_{5} \mathrm{~N}_{4} \mathrm{O}_{2}$. Z. Kristallogr. N. Cryst. Struct. 2019, 234, 737-739.

27. Wyshusek M., Reiss G. J., Frank W. The triple salt $2\left(\mathrm{C}_{7} \mathrm{H}_{9} \mathrm{~N}_{4} \mathrm{O}_{2}\right)$ $\left[\mathrm{MoOCl}_{4}\left(\mathrm{H}_{2} \mathrm{O}\right)\right] \cdot 2\left(\mathrm{C}_{7} \mathrm{H}_{9} \mathrm{~N}_{4} \mathrm{O}_{2}\right) \mathrm{Cl} \cdot\left(\mathrm{H}_{17} \mathrm{O}_{8}\right) \mathrm{Cl}$ containing a $\mathrm{C}_{2}$ -symmetrical unbranched $\mathrm{H}_{+}\left(\mathrm{H}_{2} \mathrm{O}\right)_{8}$ Zundel type species in a framework composed of Theophyllinium, aquatetrachloridooxidomolybdate and chloride ions. Z. Anorg. Allg. Chem. 2021, 647, 575-581.

28. Groom C. R., Bruno I. J., Lightfoot M. P., Ward S. C. The Cambridge structural database. Acta Crystallogr. B 2016, 72, 171-179.

29. Megen M., Prömper S., Reiss G. J. Bis(3-azaniumylpyridin-1-ium) hexachloridostannate(IV) dichloride. Acta Crystallogr. E 2013, 69, $\mathrm{m} 217$.

30. Dolling B., Gillon A. L., Orpen A. G., Starbuck J., Wang X.-M. Homologous families of chloride-rich 4,4'-bipyridinium salt structures. Chem. Commun. 2001, 567-568; https://doi.org/10. 1039/b009467f.

31. Szafrański M. St åahl K. Phase transitions in layered diguanidinium hexachlorostannate(IV). Cryst. Growth Des. 2016, 16, 2157-2166.

32. Moussa O. B., Chebbi H., Arfaoui Y., Falvello L. R., Tomas M., Zid M. F. Structural study, vibrational and optical properties, Hirshfeld surface analysis and DFT investigation of a novel organic cation hexachloridostannate(IV), $\left(\mathrm{C}_{5} \mathrm{H}_{8} \mathrm{~N}_{3}\right)_{2}\left[\mathrm{SnCl}_{6}\right]$. J. Mol. Struct. 2019, 1195, 344-354.

33. Ferjani H. Crystal structure, optical property and Hirshfeld surface analysis of bis[1-(prop-2-en-1-yl)-1H-imidazol-3-ium] hexachloridostannate(IV). Acta Crystallogr. E 2020, 76, 1624-1628.

34. Ghallab R., Boutebdja M., Denes G., Merazig H. Synthesis, crystal structure and Hirshfeld surface of bis(2-aminopyridinium) hexachloridostannate(IV). Acta Crystallogr. E 2020, 76, 1279-1283.

35. Manonmani M., Balakrishnan C., Dhanalakshmi M., Ahamed S. R., Vinitha G., Sockalingam R. M. Synthesis, structure, thirdorder nonlinear optical properties and Hirshfeld surface analysis of tetrakis(azepanium) hexachlorostannate(IV) dichloride and tetrakis(azepanium) hexabromostannate(IV) dibromide. J. Mol. Struct. 2021, 1227, 129515.

36. Hajji R., Fersi M. A., Hajji S., Hlel F., Ben Ahmed A. Hirshfeld surface analysis, vibrational spectra, optical, DFT studies and biological activities of $\left(\mathrm{C}_{7} \mathrm{H}_{12} \mathrm{~N}_{2}\right) 2\left[\mathrm{SnCl}_{6}\right] \mathrm{C}_{12} \cdot 1.5 \mathrm{H}_{2} \mathrm{O}$ compound. Chem. Phys. Lett. 2019, 722, 160-172.

37. Klösener J., Wiesemann M., Neumann B., Stammler H.-G., Hoge B. Hypercoordinated fluoro(pentafluoroethyl)stannanes and -stannates. Eur. J. Inorg. Chem. 2018, 2018, 3960-3970.

38. Lee S. M., Lo K. M., Tiekink E. R. T. Crystal structure of 2-(pyridin2-ylamino)pyridinium chloride dibenzyldichlorostannane, $\left[\mathrm{C}_{10} \mathrm{H}_{10} \mathrm{~N}_{3}\right] \mathrm{Cl}, \mathrm{C}_{14} \mathrm{H}_{14} \mathrm{C}_{12} \mathrm{Sn}$. Z. Kristallogr. N. Cryst. Struct. 2020, 235, 1515-1517.

39. Reiss G. J. The pseudosymmetric structure of bis(diisopropylammonium) hexachloroiridate(IV) and its relationship to potassium hexachloroiridate(III). Acta Crystallogr. E 2002, 58, m47-m50. and cited references.

40. Brockner W., Demiray A. F. Raman-Spektroskopische Untersuchungen an $\mathrm{PCl}$. IV. Das System $\mathrm{PCl}_{5}-\mathrm{SnCl}_{4}$. Z. Naturforsch. 1979, 34, 976-978.

41. Pelzl J., Engels P., Florian F. Raman spectroscopic study of the structural phase transitions in $\mathrm{K}_{2} \mathrm{SnCl}_{6}$. Phys. Status Solidi $B$ 1977, 82, 145-148.

42. Baggio R. A simple graphical method to pinpoint local pseudosymmetries in Z' >1 cases. Acta Crystallogr. C 2019, 75, 837-850.

43. Baggio R R. Playing around with MP, a tool for the analysis of pseudosymmetry: recurrent appearance of local pseudo-space groups in the asymmetric unit of $Z^{\prime}=4$ structures. Acta Crystallogr. C 2020, 76, 258-268.

44. Somov N. V., Chuprunov E. V. The translational and inversion pseudosymmetry of the atomic crystal structures of organic and organometallic compounds. Crystallogr. Rep. 2009, 54, 773-779.

45. Ruck M. Kristallographische Konsequenzen von Pseudosymmetrie in Kristallstrukturen. Z. Kristallogr. - Cryst. Mater. 2000, 215, 148-156.

46. Ouasri A., Rhandour A., Schloots S., Reiss G. J. The crystal structure of bis(diethylammonium) hexachloridoplumbate(IV) derived from powder diffraction data and its relation to structurally related hexachloridometallate salts. J. Chem. Crystallogr. 2017, 47, 173-181. 